\title{
Assessment of Clinical and Investigations Probabilities for Pulmonary Embolism
}

Fayez El. Mohamed ${ }^{{ }^{*}}$, Ismail A. Attia ${ }^{2}$, Moustafa F. Mohamed ${ }^{2}$ and Sameh F. Mekled ${ }^{2}$

${ }^{1}$ Department of Chest Diseases, khafr Elshikh Chest Hospital

${ }^{2}$ Department of Chest Diseases, Faculty of Medicine, Al-Azhar University

*Corresponding Author: Fayez Elzeny Mohamed, E-Mail: Mhamedfayez63@ gmail.com,

Mobile: 01014506265

\begin{abstract}
Background: pulmonary embolism (PE) is one of the most frequent diseases that could be missed in overcrowded emergency departments. Early and accurate diagnosis could decrease the mortality rate and this standard algorithm should be defined.

Aim: The aim of this study was to evaluate the role of estimating clinical probability of pulmonary embolism and to reveal which a combination of presented clinical data that is more predictable to PE.

Patients and Methods: The study included 50 patients with suspected pulmonary embolism, admitted to El Hussein and Sayed Galal University hospitals.

Results: according clinical probability of patients $90 \%$ of patients from 50 cases were approved positive by CT pulmonary angio. In the current study we found that sensitivity accuracy of clinical probability in diagnosing pulmonary embolism in comparison to CT pulmonary angio was $90 \%$.

Conclusion: clinical probability of pulmonary embolism was efficient like other diagnostic methods, so biochemical parameters, clinical findings, and scoring systems, when used altogether, can contribute to the diagnosis of PE.
\end{abstract}

Keywords: age-adjusted D-dimer cut-off,clinical prediction rules,diagnostic tests,pulmonary embolism.

\section{INTRODUCTION}

Pulmonary embolism (PE) is an obstructive disease of the pulmonary arterial system occurring in different stages and locations. It is commonly caused by the embolization of thrombus originating from the deep veins of the lower extremities. PE is the third cause of cardiovascular related deaths after coronary arterial diseases and stroke. The mortality rate can be decreased to $3 \%$ by appropriate diagnosis and medication ${ }^{(1)}$.

The differential diagnosis of PE consists of commonly seen diseases. Its symptoms and findings are non-specific, and clinical diagnosis is not reliable. PE can be overlooked because of comorbidities, and the diagnosis can be delayed ${ }^{(\mathbf{1})}$.

Pretest clinical probability assessment is the first step in modern diagnostic strategies for pulmonary embolism (PE) ${ }^{(2)}$. The assessment of pretest clinical probability may be performed either empirically or by the means of clinical prediction rules (CPRs). CPRs are decision- making tools that allow a standardized and reliable assessment of clinical probability. CPRs have also been shown to be associated with a better interobserver agreement and their accuracy is not dependent on the level of experience of physicians. Moreover, the use of CPRs has been associated with better patients' outcomes and implementation of CPRs in daily clinical practice is widely recommended to improve the safety of diagnostic strategies for venous thromboembolism (3). We aimed in this study to evaluate the role of estimating clinical probability of pulmonary embolism and to reveal which a combination of presented clinical data that is more predictable to pulmonary embolism.

\section{PATIENTS AND METHODS}

This prospective study included a total of 50 patients with suspected pulmonary embolism, admitted to El Hussein and Sayed Galal University hospitals and khafr Elshikh chest hospital in the period from Desember 2017 to July 2018.

\section{Ethical approval}

The study was approved by the Ethics Board of Al-Azhar University and an informed written consent was taken from each participant in the study.

\section{Inclusion criteria:}

Patients with suspected pulmonary embolism.

\section{Exclusion criteria:}

1- Patients aged below 18 who had PE.

2- Patients with acute coronary syndrome or infection.

3- Patients with chronic obstructive pulmonary disease (COPD).

4- Patients with right ventricular loading.

\section{Methods:}

Full history taking:

1- History of risk factors to PE as previous DVT, recent surgery or fracture within 4 weeks, active malignancy and prolonged immobilization.

2- History of symptoms as chest pain, hemoptysis and acute dyspnea. 


\section{Clinical examination:}

1- General examination for unilateral leg edema, tachycardia, hypotension and collapse and central cyanosis.

2- Local examination for tachypnea, signs of pleural effusion or diaphragmatic copula elevation.

\section{Investigations:}

1- Primary investigations including plain chest x- ray, ECG, Echocardiography and D-Dimer. Other routine investigations as CBC, ESR, liver and kidney functions were done.

2- C.T pulmonary angiography was the confirmatory investigation for PE.

\section{Statistical Analysis of Data:}

The collected data organized, tabulated and statistically analyzed using statistical package for social sciences (SPSS) version 22 (SPSS Inc, Chicago, USA). For qualitative data, frequency and percent distributions was calculated. For quantitative data, mean, standard Error (SE), minimum and maximum was calculated. Statistical significance was defined as $\mathrm{P}$ value $<0.05$.

\section{The following tests were done:}

- Independent-samples t-test of significance was used when comparing between two means.

- The confidence interval was set to $95 \%$ and the margin of error accepted was set to $5 \%$. The p-value was considered significant as the following:

- P-value $<0.05$ was considered significant.

- P-value <0.001 was considered as highly significant.

- P-value >0.05 was considered insignificant.

\section{RESULTS}

This study was conducted on 50 patients with mean age of 67.28 years with male predominance about $68 \%$ (table1), $32 \%$ of patients had hyperlipidemia, $24 \%$ had hypertension, $20 \%$ had diabetes mellitus, $16 \%$ had coronary heart disease and $8 \%$ had chronic renal failure, $24 \%$ of patients were smokers, $18 \%$ had active malignancy, $8 \%$ had recent surgery, $20 \%$ had recent immobilization, $20 \%$ had history of previous PE DVT, $10 \%$ had Central Cyanosis and $16 \%$ had Diaphragmatic elevation.

Regarding Pleural effusion 22\% had Pleural effusion, $70 \%$ had Tachypnea, $64 \%$ had Tachycardia hypotension, $24 \%$ had unilateral leg oedema, $70 \%$ had acute dyspnea, 46\% had Hemoptysis and 70\% had chest pain.

Regarding laboratory investigation we found that $12 \%$ had abnormal CBC, $34 \%$ had abnormal CRP, 6\% had abnormal liver function, 16\% had abnormal kidney function, all patients had positive
D-Dimer, $16 \%$ had abnormal ESR and $34 \%$ had abnormal ABG.

Other investigations revealed that $34 \%$ had abnormal Chest X ray, 64\% had abnormal Echo, $40 \%$ had abnormal Doppler, $82 \%$ of patients had abnormal ECG and all patients had abnormal CT Pulmonary Angiography.

The most common risk factor among patients was active malignancy in $26 \%$ of patients followed by recent surgery in 16\%, immobilization in $10 \%$ and DVT in $8 \%$ (table 2) .

According clinical probability of patients 45 cases were positive $90 \%$ of patients from 50 cases were approved positive by CT pulmonary angio, Rt pulmonary artery appears affected by CT Pulmonary Angio in $46 \%$ of patients and $54.0 \%$ had $\mathrm{Lt}$ pulmonary artery (table 3, fig. 1).

Sensitivity, accuracy of clinical probability in diagnosing pulmonary embolism in comparison to CT pulmonary angio were $90 \%$ (table4).

Table (1): Distribution of the studied cases according to age and sex $(n=50)$

\begin{tabular}{|c|c|c|}
\hline & No. & $\%$ \\
\hline $\begin{array}{l}\text { Age (years): } \\
<60 \\
60-79 \\
\geq 80\end{array}$ & $\begin{array}{c}8 \\
40 \\
2\end{array}$ & $\begin{array}{c}16.0 \\
80.0 \\
4.0\end{array}$ \\
\hline $\begin{array}{l}\text { Min. }- \text { Max. } \\
\text { Mean } \pm \text { SD. } \\
\text { Median }\end{array}$ & \multicolumn{2}{|c|}{$\begin{array}{c}54.0-80.0 \\
67.28 \pm 7.27 \\
67.0 \\
\end{array}$} \\
\hline $\begin{array}{l}\text { Sex: } \\
\quad \text { Male } \\
\text { Female }\end{array}$ & $\begin{array}{l}34 \\
16\end{array}$ & $\begin{array}{l}68.0 \\
32.0\end{array}$ \\
\hline
\end{tabular}

Table (2): Risk factor for PE among cases of the study

\begin{tabular}{|c|c|c|}
\hline Risk Factor & $\mathbf{N}$ & $(\boldsymbol{\%})$ \\
\hline $\begin{array}{c}\text { Active } \\
\text { Malignancy }\end{array}$ & 13 & 26 \\
\hline immobilization & 5 & 10 \\
\hline Recent surgery & 8 & 16 \\
\hline DVT & 4 & 8 \\
\hline
\end{tabular}

Table (3): Distribution of the different studied cases according to CT Pulmonary Angiography and PE by clinical probability $(\mathrm{n}=50)$

\begin{tabular}{|l|c|c|c|c|}
\hline \multicolumn{2}{|c|}{} & \multicolumn{2}{|c|}{ Positive } & \multicolumn{2}{c|}{ Negative } \\
\cline { 2 - 5 } & No. & $\%$ & No. & $\%$ \\
\hline $\begin{array}{l}\text { CT Pulmonary } \\
\text { Angiography }\end{array}$ & 50 & 100 & 0 & 0 \\
\hline $\begin{array}{l}\text { PE by clinical } \\
\text { probability }\end{array}$ & 45 & 90.0 & 5 & 10.0 \\
\hline
\end{tabular}




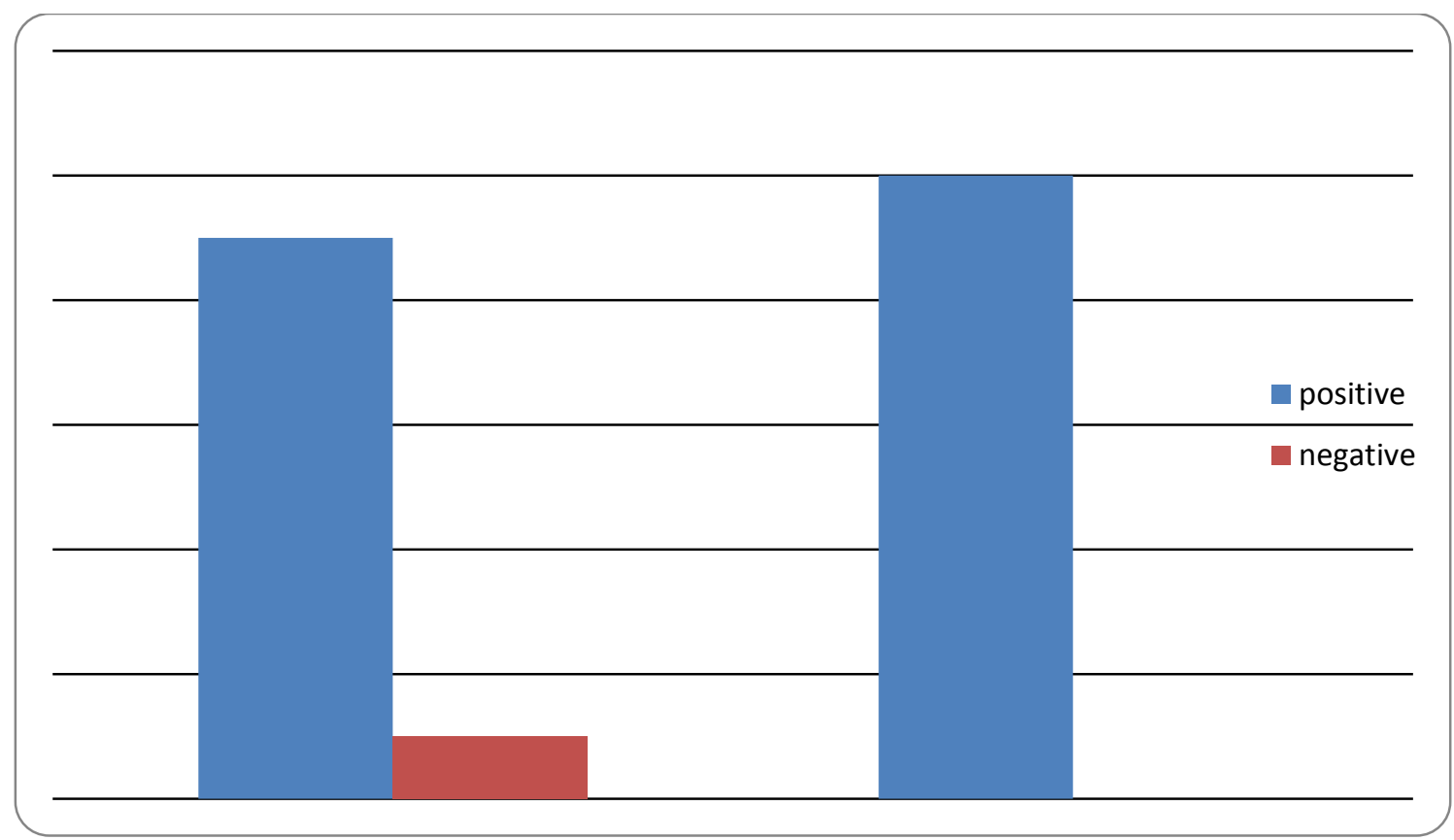

Figure (1): Distribution of the different studied cases according to CT Pulmonary Angio and PE by clinical probability

Table (4): Agreement (sensitivity, specificity and accuracy) for PE by clinical probability ( $n=50)$

\begin{tabular}{|c|c|c|c|c|c|c|c|c|c|}
\hline & \multicolumn{4}{|c|}{ CT Pulmonary Angio } & \multirow{3}{*}{ Sensitivity } & \multirow{3}{*}{ Specificity } & \multirow{3}{*}{ PPV } & \multirow{3}{*}{ NPV } & \multirow{3}{*}{ Accuracy } \\
\hline & \multicolumn{2}{|c|}{$\begin{array}{l}-v e \\
(n=0)\end{array}$} & \multicolumn{2}{|c|}{$\begin{array}{l}+\mathrm{ve} \\
(\mathbf{n}=50)\end{array}$} & & & & & \\
\hline & No. & $\%$ & No. & $\%$ & & & & & \\
\hline $\begin{array}{l}\text { PE by clinical probability } \\
\text {-ve } \\
\text { +ve }\end{array}$ & $\begin{array}{l}0 \\
0\end{array}$ & $\begin{array}{l}0.0 \\
0.0\end{array}$ & $\begin{array}{l}5 \\
45\end{array}$ & $\begin{array}{l}10.0 \\
90.0\end{array}$ & 90.0 & - & 100.0 & 0.0 & 90.0 \\
\hline
\end{tabular}

\section{DISCUSSION}

Suspected acute pulmonary embolism (PE) is a common cause for acute hospital attendance and admission. Clinical assessment is necessary to estimate a pre-test probability of PE and determine what (if any) diagnostic testing is required. Clinical assessment may be used in an unstructured manner to generate a pre-test estimate of probability or may be used in a formal clinical probability score to categorize patients into (typically) low, intermediate or high-risk groups ${ }^{(4)}$.

In the current study, we found that mean age of studied patients was 67.28 years with male predominance about $68 \%$. A total of 1090 consecutive patients were evaluated by Wicki et $\boldsymbol{a l} .^{(5)}$ and found that median age of the patients was 62 years (range, 17-97 years), in ADJUST-PE study $(\mathrm{n}=1621)$ female was predominant with $56 \%$ and median age 63 (53-74)years ${ }^{(6)}$.

In the current study we found that $32 \%$ of patients had hyperlipidemia, $24 \%$ had hypertension, $20 \%$ had diabetes mellitus, $16 \%$ had coronary heart disease and $8 \%$ had chronic renal failure. $24 \%$ of patients were smokers, $18 \%$ had active malignancy, $8 \%$ recent surgery, $20 \%$ recent immobilization and $10 \%$ had history of previous PE DVT.

In Robert-Ebadi et al. ${ }^{(3)}$ they found that $14.1 \%$ of patient had history of venous thromboembolic event, 5.7\% Active malignancy, $3.0 \%$ Surgery within 1 month .

In the current study we found that $70 \%$ of patients represented by tachypnea, acute dyspnea and chest pain, $64 \%$ with tachycardia hypotension, $46 \%$ with hemoptysis.

In Robert-Ebadi et al. $^{(3)}$ study they found that $69.0 \%$ had chest pain, $65.1 \%$ had Dyspnea, $3.9 \%$ Hemoptysis,another study by Klok et al. $^{(\mathbf{6})}$ found that $70.3 \%$ had chest pain, $65.7 \%$ had Dyspnea, $4.5 \%$ Hemoptysis.

In the current study we found that all patients had abnormal D-Dimer test, 34\% had abnormal ABG,CRP ,24\% had abnormal ESR,16\% had abnormal kidney function, $12 \%$ had abnormal CBC and $6 \%$ had abnormal liver function. all patients had 
positive CT pulmonary angio for pulmonary embolism. $82 \%$ had abnormal ECG finding,64\% had abnormal echo ,40\% had abnormal Doppler and 34\% had abnormal chest $\mathrm{X}$ ray.

ECG findings are nonspecific for the diagnosis of PE, but they are useful to rule out diseases like acute myocardial infarction (MI) and pericarditis. In a studydone by Torbicki et al. ${ }^{(9)}$ in which ECG findings were found to be abnormal in $70 \%$ of patients, the most common pathological findings were sinus tachycardia, S1Q3T3 pattern, $\mathrm{T}$ wave inversion and atrial fibrillation.

In the current study we found that there was significant relation between age, recent surgery, recent immobilization, previous PE DVT and clinical probability of pulmonary embolism.

In agreement with our result Wicki et al. ${ }^{(5)}$ found that in multivariate analysis, 8 predictors showed a significant association with PE: recent surgery, previous thromboembolic event, older age, hypocapnia, hypoxemia, tachycardia, platelike atelectasis, or elevation of a hemidiaphragm on chest $\mathrm{x}$-ray film.

Miniati et al. ${ }^{(7)}$ defined immobilization, history of thrombophlebitis, malignancy and lower extremity fractures as significant risk factors.

In the current study we found that according clinical probability of patients 45 cases were positive 90\% of patients from 50 cases were approved positive by CT pulmonary angio. In the current study we found that sensitivity accuracy of clinical probability in diagnosing pulmonary embolism in comparison to CT pulmonary angio were $90 \%$.

Sanjuán et al. ${ }^{\left({ }^{(8)}\right.}$ found that the prevalence of $\mathrm{PE}$ varied depending on Clinical probability $(\mathrm{CP})$ : $4.8 \%$ [61/1281] in the low probability group, $13.1 \%$ [241/1837] in the intermediate probability group, and $40.3 \%(50 / 124)$ in the high probability group $(\mathrm{P}<.001$ comparing all of them)

$\mathrm{PE}$ was diagnosed in 8 more cases among the 682 patients in whom CP calculation was not possible. Overall prevalence of $\mathrm{PE}$ was $9.2 \%$ (360/3924) and incidence was 30.6 cases per 100000 inhabitants/year. DD was determined in $94.7 \%$ of cases (3071/3242). Its sensitivity for the diagnosis of PE was $98.7 \%$, and the negative predictive value was $99.2 \%{ }^{(8)}$.

In a study by Wicki et $_{\text {al. }}{ }^{(5)}$ they also trying to assess clinical probability in diagnosing pulmonary embolism by forming clinical score and they found that The accuracy of the empirical assessment is similar to that of the prediction by the score. The score tended to identify the patients with a high clinical probability more accurately than empirical evaluation (prevalence of PE: $81 \%$ vs $66 \%$, respectively), but the difference did not reach statistical significance and this goes with our result.

\section{CONCLUSION}

In the current study we conclude that clinical probability of pulmonary embolism was efficient like other diagnostic methods so Biochemical parameters, clinical findings, and scoring systems, when used altogether, can contribute to the diagnosis of PE.

\section{REFERENCES}

1. Yetgin GO, Aydin SA, Koksal O, Ozdemir F, Mert DK, Torun G (2014): Clinical probability and risk analysis of patients with suspected pulmonary embolism. World J Emerg Med., 5(4):264-269.

2. Konstantinides SV (2014) : ESC Guidelines on the diagnosis and management of acute pulmonary embolism. Eur Heart J .,35: 3145-6.

3. Robert-Ebadi H, Mostaguir K, Hovens MM et al. (2017): Assessing clinical probability of pulmonary embolism : prospective validation of the simplified Geneva score. J Thromb Haemost., 15: 1764-9.

4. El Wahsh RA, Agha MA (2012): Clinical probability of pulmonary embolism: Comparison of different scoring systems. Egyptian Journal of Chest Diseases and Tuberculosis, 61: 419-424.

5. Wicki J, Perneger TV, Junod AF, Bounameaux H, Perrier A (2001) : Assessing Clinical Probability of Pulmonary Embolism in the Emergency Ward. Arch Intern Med.,161:92-97.

6. Klok FA, Mos IC, Huisman MV (2008) : Brain-type natriuretic peptide levels in the prediction of adverse outcome in patients with pulmonary embolism: a systematic review and meta-analysis.Am J RespirCrit Care Med.,178(4):425-430.

7. Miniati M, Prediletto R, Formichi B, Marini C, Di Ricco G, Tonelli L, Allescia G, Pistolesi M (1999) : Accuracy of clinical assessment in the diagnosis of pulmonary embolism. Am J Respir Crit Care Med.,159:864-871.

8. Sanjuán $P$, Rodríguez-Núnez $N$, Rábade $C$, Lama A, Ferreiro L, González Barcala FJ (2014) : Probability Scores and Diagnostic Algorithms in PulmonaryEmbolism: Are They Followed in Clinical Practice?.Arch Bronconeumol.,50:172-17.

9. Torbicki A, Van Beek E, Charbonnier B (2000) : Guidelines on diagnosis and management of acute pulmonary embolism. EurHeart J., 21: 1301-1336. 